\title{
The genetic transformation of bone biology
}

\author{
Gerard Karsenty ${ }^{1}$ \\ Department of Molecular and Human Genetics, Baylor College of Medicine, Houston, Texas 77030
}

The skeleton, like every organ, has specific developmental and functional characteristics that define its identity in biologic and pathologic terms. Skeleton is composed of multiple elements of various shapes and origins spread throughout the body. Most of these skeletal elements are formed by two different tissues, cartilage and bone, and each of these two tissues has its own specific cell types: the chondrocyte in cartilage, and the osteoblast and osteoclast in bone. Finally, each of these cell types has its own differentiation pathway, physiological functions, and therefore pathological conditions. The complexity of this organ in terms of developmental biology, physiology, and pathology, along with the multitude of important conceptual advances in our understanding of skeletal biology, are such that it has become impossible to present in a short review an up-to-date summary of both cartilage and bone biology. Thus, this review will concentrate only on bone biology beyond embryonic patterning. The entire bone field is dominated by the impact of degenerative diseases, such as osteoporosis. This mere fact does influence the research in bone biology and will influence the topics presented in this review. It is no surprise that, like for most other organogenesis processes, human and mouse genetic studies have been a major driving force in redefining bone biology. Genetic studies have opened new areas of research, elucidated at the molecular level some known phenomena, and sometimes challenged untested textbook assumptions, thus transforming the field profoundly.

In mammals, bone development is a late embryonic event as it is the last event of skeleton development. Once the mesenchymal condensations prefiguring each future skeletal element have formed, between 10.5 and 12.5 days postcoitum (dpc) in mouse, they can evolve along two different paths. In some skeletal elements, prefiguring part of the skull and the clavicles, the cells of the mesenchymal condensations differentiate directly into osteoblasts that appear at $15.5 \mathrm{dpc}$ of mouse development (Hall and Miyake 1992; Huang et al. 1997). This process is called intramembranous ossification. For the rest of the future skeleton, cells of the mesenchymal

This paper is dedicated to the memory of Dr. Louis Avioli. ${ }^{1}$ Corresponding author.

E-MAIL karsenty@bcm.tmc.edu; FAX (713) 798-1465. condensations differentiate into chondrocytes forming the "cartilage anlagen" of the future bones. In the periphery of the anlage, cells from the perichondrium differentiate into osteoblasts, while the periphery of the anlage become hypertrophic. Eventually, the matrix surrounding these hypertrophic chondrocytes calcifies and blood vessel invasion of the calcified cartilage brings in osteoblasts 14.5-15.5 dpc (Horton 1993; Erlebacher et al. 1995). Once a bone matrix is deposited the bone marrow forms and the first osteoclasts appear (Hofstetter et al. 1995). Thus, sequential appearance of a cartilage anlage, calcified cartilage, and then bona fide bone characterizes the endochondral ossification. Regardless of the mode of ossification, osteoblast differentiation precedes osteoclast differentiation.

One peculiar characteristic of bone resides in its physiology. Bone is the only organ that contains a cell type, the osteoclast, whose only function is to constantly destroy the organ hosting it. This destruction, or resorption, of bone occurs throughout life and in healthy individuals is counterbalanced by de novo bone formation in a process called bone remodeling (Frost 1969). It is through bone remodeling that bone mass is maintained at a constant level between the end of puberty and gonadal failure, and bone remodeling is the process affected during osteoporosis, a disease characterized at the cellular level by a relative increase of bone resorption over bone formation (Rodan et al. 1996). Recently, we have begun to understand at the molecular level how bone resorption is controlled. It is striking how little we know about the molecular mechanisms governing bone formation.

The first goal of this review is to present an up-to-date perspective on the genetic control of cell differentiation in the skeleton. The second goal is to describe our current understanding of bone physiology and pathology. The last and most elusive goal is to use our current knowledge of bone biology to formulate, along the way, some of the novel questions that need to be addressed. Before going any further in this review a few definitions are important as these words will be commonly used to summarize phenotypic abnormalities. A loss of function of the osteoclast leads to osteopetrosis, a gain of function of the osteoblast leads to osteosclerosis, and a relative increase of bone resorption over bone formation results in osteoporosis. 


\section{Regulation of osteoclast differentiation and function}

By far, the aspect of bone biology that has made the most progress in the last few years is the genetic control of osteoclast differentiation and function. This is why the biology of the osteoclast, the cell type resorbing mineralized bone matrix, is discussed first in this review even though it is the last specific cell type of the skeleton to appear during development. The systematic and logical study of many mouse mutants generated to study osteoclast differentiation or, more often for other reasons, has led to the establishment of a fairly detailed genetic cascade controlling either osteoclast differentiation or function. Some of this progress has important implications not only for bone resorption but is also, as discussed below, leading to novel hypotheses about the molecular control of bone formation.

The osteoclast belongs to the monocyte/macrophage cell lineage (Teitelbaum et al. 1996). Phenotypically, the osteoclasts are distinct from other cells in this lineage as it is a giant multinucleated cell (1-50 nuclei per cell depending of the species) found in contact with calcified bone surfaces. Only a relatively small number of genes have been shown to be expressed in osteoclasts and not in other monocyte/macrophage cells, yet more regulatory genes have been shown to control osteoclast differentiation than for any other cell type in the skeleton.

\section{Transcriptional control of osteoclast differentiation and function}

A recurrent theme in bone biology is that many of the genes that were identified as regulators of cell differentiation or function have been known for a long time. Yet, perhaps because bone cells are more difficult to isolate, or because skeletogenesis appeared less attractive initially than other processes of organogenesis, they were not originally studied in the context of the skeleton. Pu.1 function in osteoclast differentiation is one of the best illustrations of this.

Pu. 1 is an ETS domain-containing transcription factor that is expressed specifically in the monocytic and B lymphoid lineages (Klemsz et al. 1990). It has been known for several years that the deletion of Pu.1 results in a multilineage defect in the generation of progenitors for B and T lymphocytes, monocytes, and granulocytes (Scott et al. 1994; McKercher et al. 1996). The fact that $\mathrm{Pu} .1$ was thought to regulate transcription of $c-f m s$, the gene encoding the receptor for M-CSF (Sherr et al. 1985), which plays an important role in osteoclast biology (see below), led Tondravi et al. (1996) to explore the possibility that Pu.1 might also control osteoclast development. As hypothesized by this group, Pu.1-deficient mice exhibit a classical osteopetrosis phenotype. There are no osteoclasts and no macrophages in the bone marrow of Pu.1-deficient mice. This is a cell autonomous defect that can be corrected by bone marrow transplantation. To date, Pu.1 is the earliest known marker of osteoclast differentiation as it controls both macrophage and osteoclast differentiation. No cell type decides in an autono- mous manner to differentiate along a particular lineage, thus, one of the challenges in the field will be to identify the extracellular signals that induce the expression of Pu. 1 and of other cell-specific transcription factors involved in osteoclast differentiation.

Another transcription factor that plays a critical role during osteoclast differentiation is c-fos (for review, see Grigoriadis et al. 1995). c-fos is the cellular homolog of the $\mathrm{v}$-fos oncogene and is a major component of the AP-1 transcription factor. The first indication that c-fos might play a role in bone cell differentiation came from the observation that $\mathrm{v}$-fos-containing constructs injected into rodents led to the appearance of osteosarcomas (malignant tumors of mesenchymal origin with the ability to form bone tissue) (Ward and Young 1976). Likewise, transgenic mice expressing high levels of c-fos in multiple tissues and cell types eventually developed only one type of tumor: chondroblastic osteosarcoma, and clonal cell lines derived from these transgenic mice have altered osteoblastic gene expression (Grigoriadis et al. 1993). Given the results of these overexpression types of studies it came as a surprise that the deletion of c-fos in mice led to an early arrest of osteoclast differentiation without any overt consequences on osteoblast differentiation. As a result of this block in osteoclast differentiation, the main phenotype of the c-fos-deficient mice is osteopetrosis (Johnson 1992; Wang et al. 1992). The presence of a large number of macrophages in c-fos-deficient mice places c-fos downstream of Pu.1 in the genetic pathway controlling osteoclast differentiation (Fig. 1). The osteopetrotic phenotype of the c-fos-deficient mice was rescued by bone marrow transplantation and by ex-

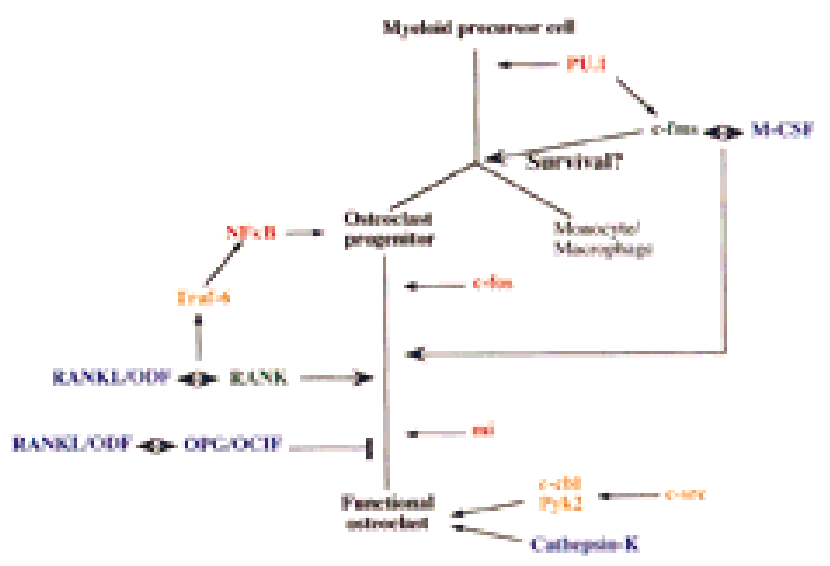

Figure 1. Genetic control of osteoclast differentiation. Osteoclasts differentiate from a myeloid progenitor cell common with macrophages. This process is under the control of the transcription factor Pu. 1 and of a growth factor, M-CSF. The latter is also involved in the maturation of differentiating osteoclastic cells, along with other secreted molecules such as RANKL/ODF, or transcription factors such as NFkB, mi or c-Fos. OPG/OCIF is a negative regulator of this process. Once maturation is achieved, factors such as c-Src, c-Cbl, Pyk2, and cathepsin K maintain the mature cells in a functional state. Transcription factors are in red, secreted factors are in blue, membrane receptors are in green, and signal transduction molecules are in orange. 
pression of a c-fos transgene (Grigoriadis et al. 1994). Although other c-fos-related proteins are expressed in osteoclasts, c-Fos fulfills a unique function as no other proteins can substitute in vivo for its loss of function. Yet, c-fos may not be the only member of the fos gene family to contribute to osteoclast differentiation, as the Fos-related protein Fra-1 can favor osteoclast differentiation in osteoclast macrophage precursor cell lines (Owens et al. 1999).

A third transcription factor, NF- $\mathrm{B}$, appears to play a role early during osteoclast differentiation. NF- $\mathrm{kB}$ is a dimer composed of various combinations of proteins: p50, p52, p65, c-Rel, and RelB (Verma et al. 1995). These proteins are all related by the Rel homology domain that contains the DNA-binding motif. Through genetic analysis in mice it was shown that each of these proteins play an essential and unique role in the immune response, although no defects in bone cell differentiation was observed (Franzoso et al. 1997; Gerondakis et al. 1998). In contrast, mice deficient in both p50 and p52 harbor an osteopetrotic phenotype because of an arrest of osteoclast differentiation (Franzoso et al. 1997; Iotsova et al. 1997). Those findings are important also because NF$\mathrm{\kappa B}$ seems to be one of the targets of recently identified growth factors that regulate osteoclast differentiation (Lomaga et al. 1999) (see below and Fig. 2).

The last transcription factor found to play a role in osteoclast differentiation was identified by searching for the gene mutated in the mouse mutant microphtalmia (mi). Heterozygous mi mice have the following defects: loss of pigmentation, reduced eye size, and failure of secondary bone resorption (Hertwig 1942). The gene mutated in these mice encodes a basic helix-loop-helix (bHLH) transcription factor called mi (Hodgkinson et al. 1993). In mi mice, osteoclasts differentiate normally, but

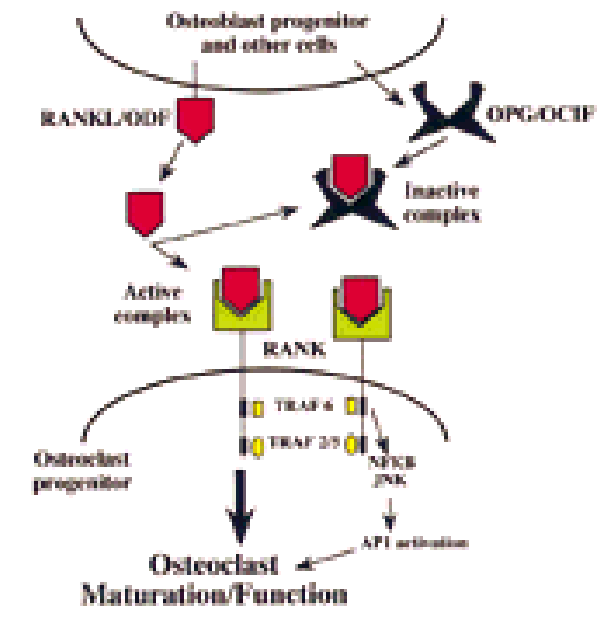

Figure 2. Regulation of osteoclast differentiation/function by TNF $\alpha$ family members. RANKL/ODF is produced by bone marrow stromal cells and $\mathrm{T}$ lymphocytes. It can be cell bound or secreted in the bone microenvironment. Its binding to the RANK receptor present on osteoclastic cells activates a transduction cascade involving TRAFs, NF- $\mathrm{KB}$, and JNK, which triggers osteoclast maturation toward a functional state. By binding to RANKL/ODF, OPG/OCIF can inhibit this process. they fail to resorb bones, thus placing mi downstream of the other transcription factors mentioned above (Fig. 1).

The wealth of transcription factors controlling osteoclast differentiation contrasting with the apparent paucity of known osteoclast-specific factors was unexpected. It suggests that many of the genes involved in bone resorption and expressed specifically in osteoclasts may not have been identified yet. Another observation common to most of these osteopetrotic mutants is that, although bone resorption was arrested, bone formation was not halted, otherwise the osteopetrosis phenotype would not exist. This is a genetic indication that bone formation is not regulated by bone resorption in vivo.

\section{Control of osteoclast differentiation and function by secreted molecules}

The requirement for secreted molecules to control osteoclast differentiation was first demonstrated with the genetic elucidation of a classical mouse mutation called op/op (Marks and Lane 1976). Mice homozygous for this recessive mutation lack osteoclasts and macrophages. The osteopetrotic phenotype of the op/op mice is not cured by bone marrow transplantation, indicating that it is not a cell autonomous defect (Marks et al. 1984). The gene mutated in osteopetrosis $(o p / o p)$ mice encodes the growth factor macrophage colony-stimulating factor (MCSF) (Yoshida et al. 1990) whose receptor synthesis is thought to be regulated by Pu-1 (Zhang et al. 1994). Forced expression of $B c 12$, a gene that prevents apoptosis in monocytes, can partially reverse the osteopetrosis of the $o p / o p$ mice, suggesting that m-CSF function may be to favor survival of osteoclast progenitors (Lagasse and Weissman 1997).

In the last 3 years a group of secreted molecules regulating osteoclast differentiation positively or negatively has been identified. The cloning and the functional analysis of these molecules have modified our understanding of bone resorption profoundly. In a systematic genomic screen for novel secreted molecules, a group at Amgen identified a novel member of the tumor necrosis factor (TNF) receptor superfamily (Simonet et al. 1997). This novel molecule contained no hydrophobic transmembrane-spanning sequence, indicating that it is a soluble receptor. Overexpression in transgenic mice of this molecule called osteoprotegerin (OPG) resulted in osteopetrosis due to an arrest of osteoclast differentiation. This molecule is identical to osteoclastogenesis inhibitory factor (OCIF) that has been purified and subsequently cloned by a group at Snowbrand Pharmaceuticals using a different approach (Yasuda et al. 1998). The identification and the functional study of OPG/OCIF showed that in addition to steroid and known peptide hormones, novel secreted molecules could act systemically to control osteoclast differentiation. The specificity of the function of OPG/OCIF in inhibiting osteoclast differentiation was illustrated by the phenotype of OPG/ OCIF-deficient mice. These mice develop an osteoporosis due to an increase in osteoclast number (Bucay et al. 1998; Mizuno et al. 1998). 
Obviously the identification of a soluble receptor with such a powerful inhibitory effect on osteoclast differentiation suggested that it might be titering out an osteoclast differentiation activity. This factor was cloned by the same two groups nearly at the same time. The Amgen group used recombinant OPG/OCIF to screen for OPG/OCIF ligand on the surface of various cell lines (Lacey et al. 1998). This time they replaced the criteria of absolute novelty by the criteria of specificity of interaction with OPG. The protein they isolated had previously been cloned and called TRANCE or RANK ligand. Heretofore, I will call it RANK ligand (RANKL) or osteoclast differentiation factor (ODF), although this nomenclature controversy is not settled. RANKL/ODF is present on the membrane of the osteoblast progenitor but can also be found as a soluble molecule in the bone microenvironment. Systemic administration of RANK/ODF leads to increased bone resorption. In vitro RANKL/ODF has all the attributes of a real osteoclast differentiation factor: It favors osteoclast differentiation in conjunction with M-CSF, it bypasses the need for stromal cells and $1,25(\mathrm{OH})_{2}$ vitamin $\mathrm{D}_{3}$ to induce osteoclast differentiation, and it activates mature osteoclasts to resorb mineralized bone (Burgess et al. 1999). Consistent with these cell and molecular biology data, RANKL-deficient mice lack osteoclasts and develop a severe osteopetrosis besides immunological defects (Kong et al. 1999). At the same time Yasuda and collegues, pursuing their biochemistry and molecular biology effort, purified to homogeneity ODF and showed that it was RANKL (Yasuda et al. 1998). Two observations are of potential interest. First, RANKL/ODF is secreted by the osteoblasts and other cells; conceivably the secreted form of OPGL/ODF could be the active form and the membrane-bound RANKL/ODF could be a reservoir of active molecule. Second, RANKL/ODF is also expressed and synthesized by $\mathrm{T}$ cells, cells that can, in vitro, induce osteoclastogenesis (Horwood et al. 1998; Rifas et al. 1998). The production and secretion of RANKL/ODF systemically or locally by T cells may explain some of the bone abnormalities observed in autoimmune disorders (Jones and Bhalla 1993; Piepkorn et al. 1997).

As mentioned above, ODF is also called RANKL because it binds to a receptor present on $\mathrm{T}$ cells and bone marrow stromal cells called RANK (Dougall et al. 1995; Anderson et al. 1997). Transgenic mice expressing a soluble form of RANK develop an osteopetrosis similar to the one observed in RANKL/ODF-deficient mice and addition of a polyclonal antibody against RANK extracellular domain promote osteoclastogenesis in bone marrow culture suggesting that RANK activation mediates the effect of OPGL/ODF (Hsu et al. 1999). The signal transduction pathway initiated following binding of RANKL/ODF to RANK has also been partly elucidated, thus establishing a cascade from extracellular signals to nuclear effectors. RANK's intracellular domain contains two binding sites for members of a family of proteins called TNF receptor-associated factors (TRAFs) (Wong et al. 1998). TRAFs have been implicated in mediating signals induced by a subset of TNF receptor family mem- bers. RANK contains a binding site for TRAF6 in its intracellular region (Darnay et al. 1999). Importantly TRAF6-deficient mice exhibit an osteopetrotic phenotype due to defective osteoclast function, thus providing the beginning of a signal transduction cascade leading to osteoclast terminal differentiation (Lomaga et al. 1999). This observation is even more important as TRAFs seem to control the activation of $\mathrm{NFkB}$, a transcription factor required for osteoclast differentiation (Franzoso et al. 1997; Iotsova et al. 1997). Given all the information available it is now possible to summarize in a cartoon form the role of each component of this signal transduction pathway (see Fig. 2).

What we learned from the OPG-RANK-RANKL story is obviously of critical importance for the control of osteoclast differentiation and function but it goes beyond that. The existence of such a tight system controlling bone resorption implies that another system of systemic regulation using proteins of the same family or of other families must control bone formation. Such a regulatory loop would be of critical importance as a target for therapeutic interventions in degenerative bone diseases such as osteoporosis.

Other cytokines such as $\mathrm{IL}_{1}, \mathrm{IL}_{6}$, oncostatin- $\mathrm{M}$, and $\mathrm{IL}_{11}$ that all transduce their signals through a composite receptor containing a gp130 subunit, can induce osteoclast differentiation in vitro (Suda et al. 1995; Manolagas et al. 1996; Mundy et al. 1996). Their role in vivo has been difficult to establish possibly because of functional redundancy. Although unpublished observations from several laboratories indicate that signal transduction through the gp130 protein plays an important role in osteoclast and osteoblast physiology, osteoclasts are present in gp130-deficient mice (Kawasaki et al. 1997).

Another regulatory gene whose functional importance in skeletal biology was revealed by mouse genetics is c-src, the cellular homolog of the v-src oncogene. c-Src, which is not a secreted protein but a membrane protein, belongs to a large family of tyrosine kinases that has been reviewed recently (Lowell and Soriano 1996). c-src is expressed ubiquitously although its highest level of expression is in platelets and neurons (Golden et al. 1986; Brugge et al. 1987). Yet its deletion led to an osteopetrotic phenotype (Soriano et al. 1991). In c-src-deficient mice, osteoclasts are present but they fail to resorb bone (Boyce et al. 1992). Consequently, the continuing bone formation in the face of impaired bone resorption leads to progressive osteopetrosis. It was later shown that the inherent defect in the Src-deficient mice was within osteoclasts and autonomous of the bone marrow microenvironment (Lowe et al. 1993). The mechanisms by which c-Src controls osteoclast function have been, and still are, the object of investigations. Schwartzberg et al. (1997) using a transgenic approach showed that rescue of the phenotype was not dependent of the kinase domain. This is one of the best illustration of the power of mouse genetics because for a long time it was thought that Src was primarily a kinase. In other lines of investigation Tanaka et al. (1996) have shown that c-cbl is a downstream gene of c-src in a signaling pathway re- 
quired for bone resorption. Duong et al. (1998) have presented evidence suggesting that phosphorylation of Pyk2 a cytoplasmic kinase activated by c-Src is required for osteoclastic bone resorption.

The list of regulatory genes controlling osteoclast differentiation and function is already surprisingly long, yet it may not be complete as there are two classical mouse mutations causing osteopetrosis for which the mutated gene has still not been identified: osteosclerotic (oc/oc) and gray lethal (Suda et al. 1996).

\section{Regulation of osteoblast differentiation and function}

The osteoblast is a cell type of mesenchymal origin that is responsible for bone matrix deposition, or bone formation. As will be discussed below, the osteoblast has another function, sometimes forgotten, and that is to be required for longitudinal bone growth. We know much less about the molecular control of osteoblast differentiation and function compared to what we know about osteoclast and chondrocyte differentiation. To date, only two genes have been shown to control osteoblast differentiation directly or indirectly, Cbfa1 and Indian hedgehog (Ihh). This relatively limited knowledge is partly attributable to the fact that the osteoblast could be viewed, from a genetic standpoint, as a sophisticated fibroblast. The osteoblast expresses all the genes expressed in a fibroblast, a cell type for which little is known in terms of differentiation, plus only a few more (Aubin and Liu 1996). Of these few extra genes one is osteoblast-enriched (Bone sialoprotein) but only one is truly osteoblast-specific in vivo (Osteocalcin).

\section{Transcriptional control of osteoblast differentiation and function}

Cbfal is the earliest and most specific marker of osteoblast differentiation known. Functional studies have shown that it is a central regulator of osteoblast differentiation and function (see Fig. 3). The names given to this gene have changed several times since it was isolated. It was originally called Pebp2a1, then Am13, and then Cbfa1 (Ogawa et al. 1993; Levanon et al. 1994; Speck and Stacy 1995). In 1995, the gene nomenclature committee decided to use the Cbfa nomenclature for all the genes of this family (Speck and Stacy 1995), and this will be used in this review. Cbfal is one of the mammalian homologs of the Drosophila transcription factor Runt (Gergen and Wieschaus 1986). Three different lines of evidence reinforcing each other demonstrate that Cbfa1 plays a role apparently not redundant with the function of any other gene during osteoblast differentiation. Following a molecular biology approach using initially the promoter of Osteocalcin as a tool to search for osteoblast-specific cis-acting elements (OSEs), Cbfa1 was identified as the factor binding to one OSE present in the promoter of most genes expressed in osteoblasts (Ducy et al. 1995, 1997; Banerjee et al. 1997; Ji et al. 1998; Jimenez et al. 1999; Porte et al. 1999|. Its expression dur- ing development and after birth is highly osteoblast-specific, and is regulated by the bone morphogenetic proteins (BMPs, see below) and other growth factors. More importantly, its ectopic expression in nonosteoblastic cells leads to the expression of osteoblast-specific genes such as Osteocalcin in these cells. All these molecular biology experiments demonstrated that Cbfal was an osteoblast differentiation factor (Ducy et al. 1997). The demonstration that this is its only function and that this function is not redundant with the function of other proteins in vivo came from mouse and human genetics experiments.

In a genetic approach, deletion of $C b f a 1$ in mice leads to mutant animals in which the skeleton was made only of chondrocytes producing a typical cartilaginous matrix without any evidence of bone (Komori et al. 1997; Otto et al. 1997). Because there was no bone in these mice, there was no bone marrow. One of the two groups who performed Cbfa1 deletion in mice explored $\mathrm{Cbfa1}^{+/-}$ mice and realized that they had hypoplastic clavicles and delay in the suture of some cranial bones (fontanelles), two bone structures that formed through intramembranous ossification (Otto et al. 1997). These abnormalities are identical to the ones observed in a classical mouse mutation called cleidocranial dysplasia (CCD) (Sillence et al. 1987). Cbfa1 maps at the same location as does $C C D$ and the two mutations are allelic (Otto et al. 1997). The third line of evidence demonstrating the role of Cbfa1 in osteoblast differentiation came from human genetics. Two groups, one looking for a gene causing human CCD and one having elucidated Cbfal biologic function and looking for a disease in which Cbfa1 was mutated, identified at the same time deletions, stop codon insertions, and missense mutations in CBFA1 in patients affected with CCD (Lee et al. 1997a; Mundlos et al. 1997).

In short, these different lines of investigation can be summarized as follows: Cbfa1 is an osteoblast-specific gene whose expression precedes the appearance of the osteoblasts; its deletion leads to a skeleton made of chondrocytes (including hypertrophic chondrocytes) in most but not all skeletal elements but is devoid of osteoblasts; and its function is dominant during osteoblast differentiation. Recently, it has been shown that Cbfa1deficient mice lack hypertrophic chondrocytes in a few skeletal elements (Inada et al. 1999; Kim et al. 1999). This may suggest that Cbfa1 is expressed in some hypertrophic chondrocytes. The significance of this observation is currently under study. As is the case for the osteoclast lineage, we do not know yet what turns on Cbfa1 expression in vivo. Although the BMPs can induce its expression in vitro, the time course needed for this induction is too long to be a direct effect and other signaling molecules must be involved. Moreover, evidence that the BMPs control the late stage of skeletogenesis, that is, osteoblast differentiation, in vivo are still missing.

Cbfa1 function in osteoblasts is not limited to cell differentiation (Fig. 3). At least one in vivo study has shown that beyond development Cbfa1 regulates the 


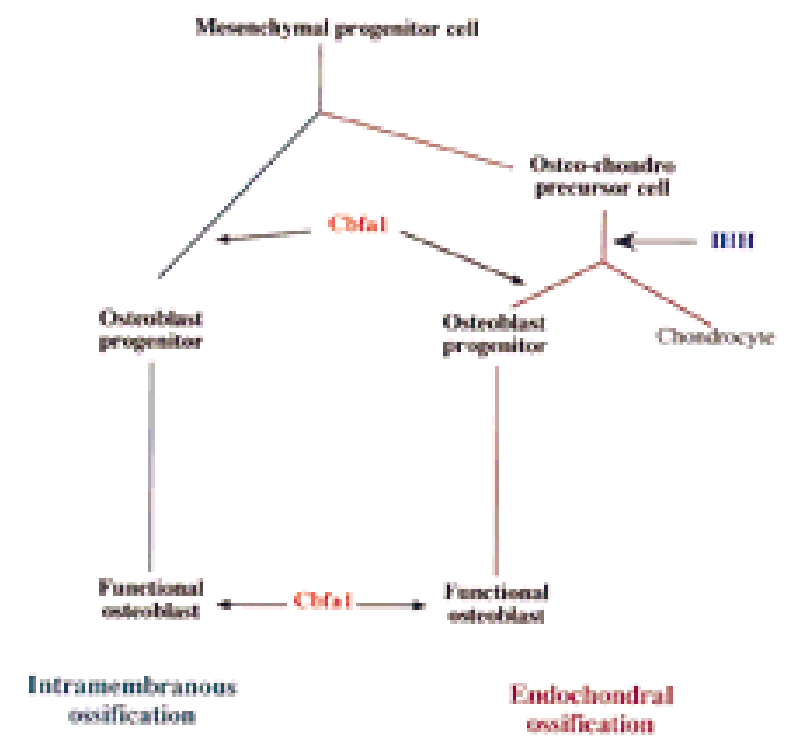

Figure 3. Genetic control of osteoblast differentiation and function. The transcription factor Cbfal is involved in controlling not only osteoblast differentiation but also osteoblast function. It is required in osteoblasts of every embryonic origin and whether they undergo endochondral or membranous ossification. In contrast, Ihh, a secreted molecule, plays a role only during endochondral ossification.

level of bone matrix deposited by already differentiated osteoblasts (Ducy et al. 1999). More experiments are in progress to further demonstrate this second function of Cbfa1, but one implication of this finding is that increasing the level of transcription of Cbfa1 in differentiated osteoblasts could be a way to prevent the appearance of osteoporosis.

Other osteoblast-specific cis-acting elements have been described in several genes that are expressed exclusively or mostly in osteoblasts suggesting that other osteoblast-specific transcription factors have yet to be identified (Ducy and Karsenty 1995; Rossert et al. 1996; Dodig et al. 1996). One of these transcription factors, provisionally termed Osf1, has been partially characterized (Schinke and Karsenty 1999). The identification and functional characterization of these other osteoblast-specific transcription factors is needed to improve, in the future, our understanding of the molecular control of osteoblast differentiation.

\section{Control of osteoblast differentiation by secreted molecules}

Ihh is one member of the Hedgehog family of growth factors that is expressed in the developing skeleton (Bitgood and McMahon 1995). Misexpression experiments in chick first identified $I h h$ as a regulator of chondrocyte differentiation (Vortkamp et al. 1996). Ihh-deficient mice that survive to birth have a disorganized growth plate as expected but they also have no osteoblasts in bone formed through endochondral ossification, whereas osteoblasts appear to be present in bones of the skull, the mandibles, and the clavicles (St-Jacques et al. 1999). At this point it is not known whether this is a direct consequence of the absence of Ihh signaling or whether it is an indirect effect. It is also difficult to know if this is a delay in osteoblast generation or an irreversible arrest of differentiation as the Ihh-deficient mice die at birth. The same group that generated Ihh-deficient mice also generated transgenic mice overexpressing Hedgehog-interacting protein (HIP) in chondrocytes (Chuang and McMahon 1999). HIP is a cell surface protein that binds Ihh with the same affinity as Patched, a receptor for Ihh, and antagonizes Ihh signaling (Chuang and McMahon 1999). Transgenic mice that overexpress HIP in chondrocytes show a chondrocyte phenotype similar to the Ihh-deficient mice and also have osteoblasts. Thus, it seems clear that the failure of osteoblast differentiation in bones forming through endochondral ossification is not a consequence of the defect in chondrocyte differentiation.

Another family of growth factors that has received, legitimately, a tremendous amount of attention are the BMPs. These secreted molecules are members of the transforming growth factor $\beta$ (TGF $\beta$ ) superfamily of growth factors that can, when applied locally, induce de novo bone formation by recapitulating all the events that occur during skeletal development (for review, see Hogan 1996; Karsenty 1998). The analysis of their functions in vivo has relied mostly on gene deletion experiments. Although several BMPs affect skeletal patterning and joint formation, it has not been possible yet using this approach, to show that they affect osteoblast differentiation. It may be attributable to functional redundancy; however, this functional redundancy does not seem to affect the function of other BMPs in organs where several of them are expressed. Alternatively, it may be that, physiologically, they act earlier during skeletal development. One approach that has not been tried at all with the BMPs, would be to overexpress them in the liver postnatally to increase their serum concentration or locally. This approach that has been so informative, for OPG, for instance, that it would help define their range of possible actions in vivo. Interestingly, one of the BMPs, BMP1, does not belong to the TGF $\beta$ superfamily but rather has homology to Tolloid, a gene product thought, based on genetic data, to be a protease in Drosophila (Shimell et al. 1991). In mouse, Bmp1 has been demonstrated to encode the protease releasing the carboxy-terminal propeptide from the type I procollagen molecule, the most abundant protein of the bone extracellular matrix (Kessler et al. 1996). Deletion of Bmp1 and other experiments have revealed the existence of other Bmp1-like or Tolloid-like proteins that may also be involved in type I collagen processing (Suzuki et al. 1996; Lee et al. 1997b).

TGF $\beta$ itself plays a complex role during bone remodeling. In vitro, TGF $\beta$ induces extracellular matrix synthesis by osteoblasts and affects osteoblast differentiation (Bonewald 1996). In vivo Erlebacher and Derynck (1996) used a local overexpression strategy to study TGF $\beta$ function. Osteocalcin-promoter-driven TGF 22 transgenic mice developed a complex low bone mass 
phenotype, characterized by an overall increase in bone resorption, a large increase of osteocyte numbers (osteoblasts embedded in matrix), and the presence of an hypomineralized matrix (Erlebacher and Derynck 1996). An increase in osteocyte number was also reported by the same group in a mouse model overexpressing a dominant negative forms of the type II TGF $\beta$ receptor in osteoblasts, suggesting that TGF $\beta$ could control the steady-state rate of osteoblast differentiation (Erlebacher et al. 1998). Additional mouse models overexpressing dominant negative forms of TGF $\beta$ receptors or affecting the level of expression of TGF $\beta$ binding proteins should allow to further define the role of TGF $\beta$ on osteoblast function.

Other growth factors such as fibroblast growth factor (FGF) and insulin-like growth factor 1 (IGF1) have been shown in vitro to favor osteoblast progenitor proliferation and differentiation, respectively (Canalis and Raisz 1980; Rodan 1987; Canalis 1993). The role of these factors in vivo has been difficult to establish because they have major functions in other developmental and physiological processes.

\section{Endocrine regulation of bone development and physiology}

Superimposed on the regulation by transcription and growth factors presented above, is an endocrine regulation of osteoblast and osteoclast differentiation and function. I discuss here only the hormones whose major sites of actions include the skeleton.

Bone is the reservoir of $99 \%$ of the extracellular calcium pool. Hormones regulating calcium levels influence cell function. Parathyroid hormone (PTH) is a hypercalcemic hormone: it prevents calcium elimination through the kidneys, and it favors the synthesis of another hypercalcemic hormone, $1,25(\mathrm{OH})_{2}$ vitamin $\mathrm{D}_{3}$, as well as bone resorption (Chorev and Rosenblatt 1996). There is no PTH-deficient mouse available yet, but there are mice and human harboring inactivating mutations of one PTH receptor. This PTH receptor is also the receptor for another ligand called PTH-related peptide (PTHrP), which controls chondrocyte differentiation (Jüppner et al. 1991; Karaplis et al. 1994). In mice and humans deficient in this receptor, there is besides the cartilage phenotype, a major increase of bone mass (Jobert et al. 1998; Lanske et al. 1999). Likewise in a mouse model of hypoparathyroidism there is also a low turnover (low number of cells) high bone mass phenotype, indicating that the overall action of PTH in the skeleton might be to favor a normal turnover and to limit the bone volume (Chisaka and Capecchi 1991).

As mentioned above, the other major hypercalcemic hormone is $1,25(\mathrm{OH})_{2}$ vitamin $\mathrm{D}_{3}$, a steroid hormone that favors intestinal absorption of calcium (Dusso and Brown 1998). Deletion or inactivation of the vitamin D receptor (VDR) in mice and in humans leads to rickets (decreased calcification of the bone), a phenotype completely reversible in both organisms by treatment with calcium (Balsan et al. 1986; Li et al. 1997, 1998;
Yoshizawa et al. 1997; Amling et al. 1999). Osteoclast differentiation is normal in VDR-deficient mice, indicating that in vivo $1,25(\mathrm{OH})_{2}$ vitamin $\mathrm{D}_{3}$ is not required for this process in vivo. The role of $1,25(\mathrm{OH})_{2}$ vitamin $\mathrm{D}_{3}$ in osteoblast differentiation is still a matter of debate. There is no overt defect of osteoblast differentiation in VDR-deficient mice. However, humans with kidney failure can develop a particular type of bone phenotype called renal osteodystrophy (Slatopolsky and Delmez 1998). Treatment of these patients with $1,25(\mathrm{OH})_{2}$ vita$\min \mathrm{D}_{3}$ has been shown to inhibit osteoblast differentiation (Goodman et al. 1994). These observations imply that $1,25(\mathrm{OH})_{2}$ vitamin $\mathrm{D}_{3}$ is an inhibitor of osteoblast differentiation. This is in agreement with the fact that treatment of primary osteoblast cultures with $1,25(\mathrm{OH})_{2}$ vitamin $\mathrm{D}_{3}$ inhibits Cbfa1 expression (Ducy et al. 1997).

Much less is known about the function in vivo of calcitonin, the last major hormone regulating serum calcium. Calcitonin is a hypocalcemic hormone secreted by the thyroid. The functional importance of calcitonin is not really understood, as thyroidectomized patients that lack calcitonin have no major metabolism abnormalities and no major bone phenotype (Hurley et al. 1987). Study of calcitonin-deficient mice should help to establish the function of this hormone (R. Gagel, pers. comm.). Calcitonin is related to two other polypeptide hormones, calcitonin gene-related product (CGRP) and amylin (Wimalawansa 1997). Amylin appears in vitro and in vivo to favor osteoblast function and to inhibit bone resorption (Cornish et al. 1998). It is the only identified secreted molecule able to act in opposite directions in both aspects of bone remodeling.

The most important hormones in bone physiology and physiopathology are the sex steroid hormones, particularly estrogens. In vivo experiments performed daily in humans have shown their importance. Osteopenia (bone loss) and osteoporosis are obligatory consequences of the estrogen deprivation characterizing the menopause, and treatment of menopaused women with estrogen prevents or corrects osteoporosis (Pacifici 1998). There are relatively few estrogen receptors in osteoblasts and even fewer in osteoclasts (Bodine et al. 1998; Oursler et al. 1998; Oreffo et al. 1999). Although the number of investigations trying to elucidate the mechanisms of action of estrogens on bone are countless, we still know virtually nothing about how they control bone remodeling. This may suggest that their mode of action on bone may be indirect via another target organ. A reader not fully versed in all the arcane and nuances of bone biology should make no mistake about it; in terms of priority and because of the major public health problem osteoporosis represents, understanding how estrogens control bone resorption is the one most important issue in the field of endocrine control of bone biology.

\section{Genetic analysis of skeletal function}

Cells of the skeleton are also involved in specific functions, such as bone growth, bone mineralization, and bone remodeling. We know suprisingly little about the 
molecular mechanisms regulating these critical functions.

\section{Longitudinal bone growth}

The osteoblast contributes, along with the chondrocyte of the growth plate, to the longitudinal growth of the skeleton. This was first proposed based on histological analysis (Warshawsky 1982). Chondrocytes from the growth plate cartilage produce cartilaginous extensions, termed spicules, that enter the region of junction between cartilage and bone, or metaphysis. The osteoblasts then adhere to the spicules and eventually add a bony matrix to the cartilage, forming what is called mixed spicules. Mixed spicules form over the entire metaphyseal surface of the growth plate. The peripheral mixed spicules are thought to anchor the metaphysis to the epiphysis. These peripheral spicules lengthen and their lengthening would act as a "hydraulic jack" to move the growth plate centrifugally. The validity of this model has been verified in vivo in multiple mouse mutant strains and in human genetic diseases.

Osteogenesis imperfecta (OI) is a genetic disease characterized by synthesis and secretion by the osteoblasts of defective type I collagen molecules, the most abundant bone extracellular matrix protein (Chu et al. 1983; Byers and Steiner 1992). In essence this is a functional deletion of the osteoblasts. There are several forms of various severity of OI but all patients affected with severe forms of OI are shorter than expected given the existence of fractures (P. Byers, pers. comm.). Likewise, in a mouse model of inducible osteoblast ablation, it has been documented that in the absence of osteoblasts there is a complete arrest of growth demonstrating that osteoblasts are required for longitudinal growth of the skeleton (Corral et al. 1998). Remarkably in this mouse model, as the osteoblasts repopulate the bones, the mice reached rapidly the exact same size as their littermates and their rate of longitudinal growth slows down. Such a tightly tuned regulation of bone growth and formation is consistent with the existence of systemic or endocrine regulators of bone formation similar to the one recently identified regulating bone resorption. Likewise, mice overexpressing a dominant-negative form of Cbfal have no functional osteoblasts and are shorter than their littermates (Ducy et al. 1999). The fact that genetic analyses showed that mouse and human bone physiology are extremely similar is important in a broader sense as it shows that mouse is a good model to study skeleton physiology. This is important as the future of bone biology resides probably more in elucidating physiologic processes.

\section{Bone mineralization}

Bones and teeth are the only tissues that mineralize under physiological conditions, whereas mineralization or calcification in any other tissue is pathologic. Thus, the question could be asked as follows: Is bone mineraliza- tion an active function requiring one or multiple genes, or rather is the absence of calcification in every other tissue an active function genetically controlled? It has long been proposed that in the bone matrix there is/are protein(s) or phosphoprotein(s) that could serve a function of nucleation at the beginning of the mineralization process (Glimcher 1989; Hunter et al. 1996). Many of the genes encoding these proteins, such as bone sialoprotein and osteopontin, have been deleted in mice so far without any overt effects on bone mineralization, indicating that these proteins do not alone control bone mineralization in vivo (Aubin et al. 1996; Liaw et al. 1998; Hunter et al. 1998). The current lack of success in identifying through genetic means initiators or activators of bone mineralization does not mean that they do not exist. Nevertheless, it raises the possibility that bone mineralization may also be explained by the absence of inhibitors of mineralization in the bone matrix. Work from Glimcher and collaborators $>40$ years ago showed that calcium and phosphate can precipitate passively on collagen, and this was viewed as an indication that collagen molecules are the initiators of mineralization (Glimcher et al. 1957). A similar ability was later shown for elastin and fibronectin (Seligman et al. 1975; Daculsi et al. 1999). If this is the case, because these molecules are not present only in bone, some proteins must prevent calcification from occurring in nonskeletal tissues. These latter proteins should be virtually absent from the bone matrix. One genetic experiment lends credence, indirectly, to the hypothesis that bone mineralization is largely a passive process. Matrix GLA protein (MGP) is a mineral-binding protein present in the extracellular matrix of arteries and cartilage but not of bone (the fact that it was isolated from demineralized bone powder could be explained by the large number of arteries present in bone) (Luo et al. 1997). Deletion of MGP in mice leads to massive calcification of arteries and cartilage demonstrating that inhibition of calcification is genetically controlled in at least these two tissues (Luo et al. 1997). Given this function of MGP, it will be now possible to test whether its ectopic expression in osteoblasts will impair bone mineralization. While the search is still on for an activator of bone mineralization, these experiments should help define the extent to which bone mineralization is a passive phenomenon.

Biology is the domain of compromises. Therefore, the notion that bone mineralization can be a passive phenomenon is neither contradictory nor exclusive with the existence of proteins favoring it. One such a protein is tissue-nonspecific alkaline phosphatase (TNSALP). TNSALP is expressed ubiquitously but particularly abundant in liver, kidney, and bone (Weiss et al. 1986). Mutations of TNSALP in humans lead to hypophosphatasia, a rare disease of various severity characterized by defects in skeletal mineralization (Caswell et al. 1989; Whyte 1994). These defects could result directly from the loss of function of the protein in the context of the bone matrix or be secondary to increased levels of circulating pyrophosphate, an inhibitor of mineralization (Whyte 1994). The lethality of the TNSALP-deficient 
mice, due to a defective metabolism of vitamin $\mathrm{B}_{6}$ has prevented the complete demonstration of one or the other cause (Waymire et al. 1995; Narisawa et al. 1997).

\section{Bone remodeling}

Cells of the osteoblast lineage are required for osteoclast differentiation, although $\mathrm{T}$ lymphocytes can do the job (Horwood et al. 1998; Rifas et al. 1998), and in vivo bone formation follows bone resorption during a bone remodeling cycle. Do these two facts necessarily imply that osteoblast and osteoclast functions are regulated by each other? This has not been demonstrated in vivo yet. As mentioned earlier, there are numerous examples provided by mouse and human genetics showing that in the absence of functional osteoclasts the osteoblasts deposit bone matrix normally (see above). This is precisely because the osteoblasts are functional, in that an osteopetrosis phenotype can develop in the absence of functional osteoclasts. In some cases, such as in the mice overexpressing OPG, the osteopetrosis was not present at birth but developed over a long period of time, clearly demonstrating that improper bone resorption does not affect bone formation (Simonet et al. 1997). On the other hand, are the osteoblasts controlling osteoclast function? This does not appear to be the case either. Transgenic mice in which the Osteocalcin promoter drives the expression of the thymidine kinase suicide gene have proven to be useful in addressing this question (Corral et al. 1998). When bone formation was completely arrested in these mice bone resorption continued unaffected. This result indicates that the bone-forming cells do not control the function of the osteoclasts although it does not exclude that the osteoblast progenitors do so. These genetic observations are not surprising. They are consistent with the identification of molecules such as OPG, and OPGL affecting bone resorption but not bone formation. They suggest that a systemic regulation of bone formation must exist.

\section{Genetic analysis of bone extracellular matrix biology}

Besides collagens, multiple proteins were found in bone matrix first and for that reason were called noncollagenous bone matrix proteins. Very often, these proteins have been given names that suggest a tight specificity of expression and a function that was not necessarily verified genetically. For the bone field, as for any field, the following statement is true: "I urge that we control our tendency to give these proteins specific names either on the basis of molecular weight or on the basis of a proposed function (not on experimentally proven function)" (Glimcher 1989).

Bone is not made only of cells; it also contains an extracellular matrix (ECM). The bone ECM contains mostly type I collagen, which account for $90 \%$ of the protein content and a slew of noncollagenous proteins and proteolytic enzymes. Mouse and human genetics have shown that most of these proteins and proteases are required for the integrity of the bone tissue, although it is not always understood how they achieve their functions at the molecular level. The first protein of the bone ECM whose function was elucidated genetically is type I collagen, a heteromeric protein made of two $\alpha 1(\mathrm{I})$ chains and one $\alpha 2$ (I) chain (Chu et al. 1983). Osteogenesis imperfecta (OI) is an autosomic-dominant disease of variable severity marked by decreased bone mineralization, spontaneous fractures, and short stature (Byers and Steiner 1992). In its worst forms the disease is lethal perinatally. The vast majority of the cases of OI are caused by stop codons, missense mutations, and deletions in the genes coding for either the $\alpha 1(\mathrm{I})$ or the $\alpha 2(\mathrm{I})$ chain (Prockop et al. 1994). Mutations decreasing synthesis of normal type I procollagen molecules result in mild phenotype, whereas mutations leading to abnormal type I procollagen molecules result in increased severity. Recent mouse models of OI have also been generated to study several manifestations of OI, such as short stature, which cannot be ascribed to defective type I collagen molecules (Bonadio et al. 1990; Khillan et al. 1991; Chipman et al. 1993). It has been proposed that the short stature of the OI patients, which cannot be accounted for only by their fractures, could be a result of a growth hormone deficiency (Marini et al. 1993). As mentioned above, in light of the growth-arrest phenotype of osteoblast-depleted transgenic mice, it may reflect the fact that the osteoblasts must deposit a bone ECM of good quality to support longitudinal growth.

Multiple noncollagenous proteins, proteoglycans, and enzymes have been deleted from the mouse genome. Here, one has to contend with the growing number of mutant mouse strains and highlight their major phenotypic abnormalities. For most of them the molecular bases of the phenotype of the mutant mice generated have not been elucidated. Osteocalcin is the only known osteoblast-specific protein (Hauschka et al. 1989). It owes its name to the presence of $\gamma$-carboxylated glutamate residues called gla residues, which can bind, with high affinity, calcium and other mineral ions. However, osteocalcin-deficient mice have no mineralization defects, and in other in vivo assays osteocalcin has no mineral-binding properties (Ducy et al. 1996; Boskey et al. 1998; T. Schinke and G. Karsenty, unpubl.). Instead, osteocalcin-deficient mice have an increased osteoblast function resulting in a high bone mass phenotype (Ducy et al. 1996). The mechanism of action of osteocalcin is for now unknown. The term osteopontin was chosen for a protein thought to act as a bridge between the cell surface and the hydroxyapatite crystals (Oldberg et al. 1986). Osteopontin-deficient mice do not have mineralization defects either. The major defect, in terms of bone biology, of the osteopontin-deficient mice is an alteration of the osteoclast formation (Liaw et al. 1998; Rittling et al. 1998). Here again, the molecular basis of this action is under study. Bone sialoprotein is another phosphoprotein of the bone matrix. Its absence in mice does not affect overtly bone mineralization but results in an increase in bone mass phenotype (J.E. Aubin, A.K. Gupta, R. Zirngbl, and J. Rossant, 1996, unpubl.). Proteo- 
glycans are thought to be required for matrix organization. Of all the proteoglycan-encoding genes that have been deleted from the genome, biglycan is one of the proteoglycans enriched in the bone matrix. Biglycan-deficient mice displayed an osteoporotic phenotype that becomes more pronounced over time (Xu et al. 1998). Finally, the function of two enzymes highly expressed in osteoclasts has been analyzed genetically. Cathepsin $\mathrm{K}$ is a lysosomal enzyme expressed at high levels in osteoclasts. Through a classical gene search approach it was shown to be the gene responsible for pycnodysostosis (Gelb et al. 1996). Nonsense, missense, and stop codon mutations of cathepsin $\mathrm{K}$ cause a disease characterized by short stature and osteosclerosis (Gelb et al. 1996; Hou et al. 1999). Mice deficient in cathepsin K have a very similar phenotype (Saftig et al. 1998). Osteoclasts express band 5 isozyme of tartrate-resistant phosphatase (TRAP), which is considered to be the most osteoclastspecific gene. Like most of the structural proteins expressed by osteoblasts, osteoclast function has been addressed by gene targeting. TRAP-deficient mice have a mild osteopetrotic phenotype (Hayman et al. 1996).

Multiple proteases are present in the cartilaginous and bone matrix. The function of one, gelatinase $\mathrm{B}$, has been genetically studied (Vu et al. 1998). This study is important for two reasons: First, of all the structural proteins and proteases of the bone matrix whose function has been studied genetically, it is the only one for which a molecular mechanism of action has been proposed; second, it affects a key event during endochondral bone formation, namely angiogenesis. Gelatinase B also called MMP-9 is a protease highly expressed during development by osteoclasts that can cleave several collagens and elastin (Vu et al. 1998). The major phenotype of MMP9-deficient mice was that their long bones were slightly shorter (Vu et al. 1998). Growth plates of the animals had a major lengthening of the zone of hypertrophic chondrocytes. Beyond 3 weeks of age, apoptosis, vascularization, and ossification remodeled this giant growth plate to produce bones of normal appearance. The critical cells whose lack of MMP-9 leads to this phenotype reside in the bone marrow as bone marrow transplantation can rescue the phenotype. These cells were called chondroclasts. Finally, growth plates from MMP-9-deficient mice show a delayed release of an angiogenic factor. A second set of experiments showed that inactivation of vascular endothelial growth factor (VEGF) completely blocked blood vessel invasion and at the same time there was an increase in the hypertrophic zone of the growth plate (Gerber et al. 1999). According to these results, VEGF made by the hypertrophic chondrocytes would be present in the cartilaginous matrix, the action of MMP-9 in the matrix would release VEGF that would then bind to its receptor on chondroclasts and activate cartilage replacement by bone (Fig. 4). In a similar line of work Liu et al. (1995) generated mice that are resistant to collagenase cleavage of type I collagen. Although the main phenotype of these mutant mice is a slow fibrosis subsequent studies showed that the bone resorption activity of PTH was strikingly diminished in these mice (Zhao et al.

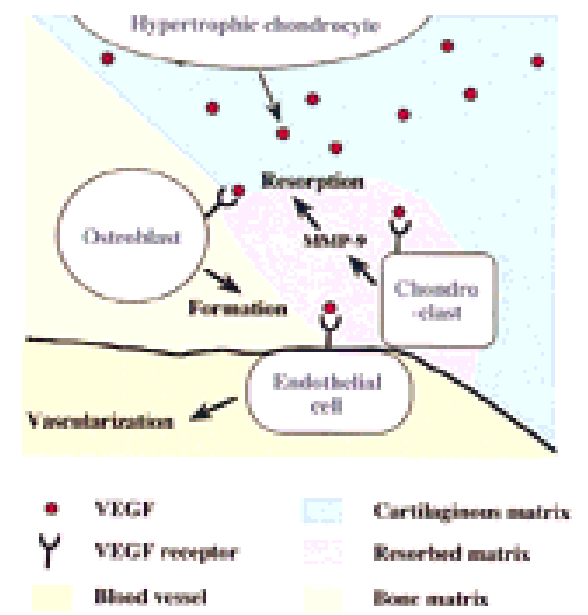

Figure 4. Role of VEGF in the control of longitudinal bone growth. VEGF is synthesized by hypertrophic chondrocytes and embedded in the cartilaginous matrix. It is released from the matrix by the action of MMP-9 secreted by chondroclasts and then binds to its receptors on endothelial cells, triggering vascular invasion, and bone matrix deposition by osteoblasts.

1999|. These examples are probably not the only examples of protease involvement in bone remodeling. The generation of more mouse strains will define the role of the multiple proteases present in the cartilaginous and bone matrix.

By identifying a role for these proteins and others that are present in the bone matrix, mouse genetics has certainly been very useful. Yet the challenges that lie ahead are nearly as enormous as before. Mouse genetics will be useful in defining domains in these proteins that are responsible for their function, but eventually we will have to rely on cell biology and biochemical assays to clearly define the mechanism of action of these gene products.

\section{Perspective}

Our understanding of bone development has advanced tremendously in the past 10 years, mostly through genetic means. Yet there is probably still much more to be learned about osteoblast differentiation. It is likely that other osteoblast-specific transcription factors besides Cbfal must exist. Their identification is required to define the genetic cascade controlling osteoblast differentiation. Likewise, the link between growth factors, such as the BMPs and others acting early during skeletal development, has still to be understood. Beyond development, our understanding of bone physiology has made important progress in the last 5 years through large screen approaches and also mouse genetics. However, we still know very little about bone physiology compared to what we know about bone development. In that respect, again the discovery of RANKL/ODF and of OPG/OCIF is of fundamental importance. It demonstrated that novel secreted molecules acting systemically and/or locally are involved in the control of bone remodeling. As mentioned above, the identification of these molecules 
affecting mostly bone resorption suggest that other molecules, yet to be recognized, must control the bone formation arm of bone remodeling. This in turn may lead to a better understanding of the mechanisms of action of the steroid hormones on bone physiology. By integrating the action of these various secreted molecules, it may be possible to define in the future several parallel pathways regulating bone physiology, one acting mostly locally and another acting systemically.

In terms of the approaches used, the history of bone biology can be divided into two parts. Initially bone biology, like most fields, was dominated by cell biology, however, in the past 10 years it has been ruled by mouse genetics. Mouse and human genetics are here to stay and rightly so. However, no single approach, whether it is cell biology, genetics, or biochemistry, will have all the answers for any field of biology. Thus, the main challenge in the short term will be to understand at the biochemical level how many of the new gene products that have been identified fulfill their functions.

\section{Acknowledgments}

I thank M. Amling, R. Baron, P. Ducy, B.R. Olsen, and T. Schinke for critical reading of the manuscript. I apologize to all authors whose work could not be directly cited owing to space limitations.

\section{References}

Amling, M., M. Priemel, T. Holzmann, K. Chapin, M. Rueger, R. Baron, and M.B. Demay. 1999. Rescue of the skeletal phenotype of vitamin D receptor ablated mice in the setting of normal mineral ion homeostasis: Formal histomorphometric and biomechanical analyses. Endocrinology (in Press).

Anderson, D.M., E. Maraskovsky, W.L. Billingsley, W.C. Dougall, M.E. Tometsko, E.R. Roux, M.C. Teepe, R.F. DuBose, D. Cosman, and L. Galibert. 1997. A homologue of the TNF receptor and its ligand enhance $\mathrm{T}$-cell growth and dendriticcell function. Nature 390: 175-179.

Aubin, J.E. and F. Liu. 1996. The osteoblast lineage. In Principles of bone biology (ed. J.P. Bilezikian, L.G. Raisz, G.A. Rodan), pp. 51-68. Academic Press, San Diego, CA.

Balsan, S., M. Garabedian, M. Larchet, A.M. Gorski, G. Cournot, C. Tau, A. Bourdeau, C. Silve, and C. Ricour. 1986. Long-term nocturnal calcium infusions can cure rickets and promote normal mineralization in hereditary resistance to 1,25-dihydroxyvitamin D. J. Clin. Invest. 77: 1661-1667.

Banerjee, C., L.R. McCabe, J.Y. Choi, S.W. Hiebert, J.L. Stein, G.S. Stein, and J.B. Lian. 1997. Runt homology domain proteins in osteoblast differentiation: AML3/CBFA1 is a major component of a bone-specific complex. I. Cell. Biochem. 66: $1-8$.

Bitgood, M.J. and A.P. McMahon. 1995. Hedgehog and Bmp genes are coexpressed at many diverse sites of cell-cell interaction in the mouse embryo. Dev. Biol. 172: 126-138.

Bodine, P.V., R.A. Henderson, J. Green, M. Aronow, T. Owen, G.S. Stein, J.B. Lian, and B.S. Komm. 1998. Estrogen receptor-alpha is developmentally regulated during osteoblast differentiation and contributes to selective responsiveness of gene expression. Endocrinology 139: 2048-2057.

Bonadio, J., T.L. Suanders, E. Tsai, S.A. Goldstein, J. Morris-
Wiman, L. Brinkley, D.F. Dolan, R.A. Altschuler, J.E. Hawkins, Jr., and J.F. Batemen. 1990. Transgenic mouse model of the mild dominant form of osteogenesis imperfecta. Proc. Nat1. Acad. Sci. 87: 7145-7149.

Bonewald, L.F. 1996. Transforming growth factor- $\beta$. In Principles of bone biology (ed. J.P. Bilezikian, L.G. Raisz, G.A. Rodan), pp. 647-659. Academic Press, San Diego, CA.

Boskey, A.L., S. Gadaleta, C. Gundberg, S.B. Doty, P. Ducy, and G. Karsenty. 1998. Fourier transform infrared microspectroscopic analysis of bones of osteocalcin-deficient mice provides insight into the function of osteocalcin. Bone 23: 187196.

Boyce, B.F., T. Yoneda, C. Lowe, P. Soriano, and G.R. Mundy. 1992. Requirement of pp60c-src expression for osteoclasts to form ruffled borders and resorb bone in mice. J. Clin. Invest. 90: $1622-1627$.

Brugge, J., P. Cotton, A. Lustig, W. Yonemoto, L. Lipsich, P. Coussens, J.N. Barrett, D. Nonner, and R.W. Keane. 1987. Characterization of the altered form of the c-src gene product in neuronal cells. Genes \& Dev. 1: 287-296.

Bucay, N., I. Sarosi, C.R. Dunstan, S. Morony, J. Tarpley, C. Capparelli, S. Scully, H.L. Tan, W. Xu, D.L. Lacey, W.J. Boyle, and W.S. Simonet. 1998. Osteoprotegerin-deficient mice develop early onset osteoporosis and arterial calcification. Genes \& Dev. 12: 1260-1268.

Burgess, T.L., Y. Qian, S. Kaufman, B.D. Ring, G. Van, C. Capparelli, M. Kelley, H. Hsu, W.J. Boyle, C.R. Dunstan, S. Hu, and D.L. Lacey. 1999. The ligand for osteoprotegerin (OPGL) directly activates mature osteoclasts. J. Cell. Biol. 145: 527538.

Byers, P.H. and R.D. Steiner. 1992. Osteogenesis imperfecta. Annu. Rev. Med. 43: 269-282.

Canalis, E. 1993. Insulinlike growth factors and the local regulation of bone formation. Bone 14: 273-276.

Canalis, E. and L. Raisz. 1980. Effect of fibroblast growth factors on cultured fetal rat calvaria. Metabolism 29: 108-114.

Caswell, A.M., R.G.G. Russell, and M.P. Whyte. 1989. Hypophosphatasia: Pediatric forms. J. Pediatr. Endocrinol. 3: 7392.

Chisaka, O. and M.R. Capecchi. 1991. Regionally restricted developmental defects resulting from targeted disruption of the mouse homeobox gene hox-1.5. Nature 350: 473-479.

Chorev, M. and M. Rosenblatt. 1996. Parathyroid hormone: Structure-function relations and analog design. In Principles of bone biology (ed. J.P. Bilezikian, L.G. Raisz, G.A. Rodan), pp. 305-323. Academic Press, san Diego, CA.

Chu, M.L., C.J. Williams, G. Pepe, J.L. Hirsch, D.J. Prockop, and F. Ramirez. 1983. Internal deletion in a collagen gene in a perinatal lethal form of osteogenesis imperfecta. Nature 304: 78-80.

Chuang, P.T. and A.P. McMahon. 1999. Vertebrate Hedgehog signalling modulated by induction of a Hedgehog-binding protein. Nature 397: 617-621.

Cornish, J., K.E. Callon, A.R. King, G.J. Cooper, and I.R. Reid. 1998. Systemic administration of amylin increases bone mass, linear growth, and adiposity in adult male mice. Am. J. Physiol. 275: E694-699.

Corral, D.A., M. Amling, M. Priemel, E. Loyer, S. Fuchs, P. Ducy, R. Baron, and G. Karsenty. 1998. Dissociation between bone resorption and bone formation in osteopenic transgenic mice. Proc. Nat1. Acad. Sci. 95: 13835-13840.

Daculsi, G., P. Pilet, M. Cottrel, and G. Guicheux. 1999. Role of fibronectin during biological apatite crystal nucleation: ultrastructural characterization. I. Biomed. Mater. Res. 47: 228-233.

Darnay, B.G., J. Ni, P.A. Moore, and B.B. Aggarwal. 1999. Acti- 
vation of NF-кB by RANK requires tumor necrosis factor receptor-associated factor (TRAF) 6 and NF-кB-inducing kinase. Identification of a novel TRAF6 interaction motif. $J$. Biol. Chem. 274: 7724-7731.

Dodig, M., M.S. Kronenberg, A. Bedalov, B.E. Kream, G. Gronowicz, S.H. Clark, K. Mack, Y.H. Liu, R. Maxon, Z.Z. Pan, W.B. Upholt, and D.W. Rowe. 1996. Identification of a TAAT-containing motif required for high level expression of the COL1A1 promoter in differentiated osteoblasts of transgenic mice. J. Biol. Chem. 271: 16422-17429.

Dougall, W.C., M. Glaccum, K. Charrier, K. Rohrbach, K. Brasel, T. De Smedt, E. Daro, J. Smith, M.E. Tometsko, C.R. Maliszewski et al. 1999. RANK is essential for osteoclast and lymph node development. Genes \& Dev. 13: 2412-2424.

Duong, L.T., P.T. Lakkakorpi, I. Nakamura, M. Machwate, R.M. Nagy, and G.A. Rodan. 1998. PYK2 in osteoclasts is an adhesion kinase, localized in the sealing zone, activated by ligation of $\alpha(\mathrm{v}) \beta 3$ integrin, and phosphorylated by src kinase. J. Clin. Invest. 102: 881-892.

Ducy, P. and G. Karsenty. 1995. Two distinct osteoblast-specific cis-acting elements control expression of $a$ mouse osteocalcin gene. Mol. Cell. Biol. 15: 1858-1869.

Ducy, P., C. Desbois, B. Boyce, G. Pinero, B. Story, C. Dunstan, E. Smith, J. Bonadio, S. Goldstein, C. Gundberg, A. Bradley, and G. Karsenty. 1996. Increased bone formation in osteocalcin-deficient mice. Nature 382: 448-452.

Ducy, P., R. Zhang, V. Geoffroy, A.L. Ridall, and G. Karsenty. 1997. Osf2/Cbfa1: A transcriptional activator of osteoblast differentiation. Cell 89: 747-754.

Ducy, P., M. Starbuck, M. Priemel, J. Shen, G. Pinero, V. Geoffroy, M. Amling, and G. Karsenty. 1999. A Cbfa1-dependent genetic pathway controls bone formation beyond embryonic development. Genes \& Dev. 13: 1025-1036.

Dusso, A.S. and A.J. Brown. 1998. Mechanism of vitamin D action and its regulation. Am. J. Kidney Dis. 32: S13-24.

Erlebacher, A. and R. Derynck. 1996. Increased expression of TGF-beta 2 in osteoblasts results in an osteoporosis-like phenotype. J. Cell. Biol. 132: 195-210.

Erlebacher, A., E.H. Filvaroff, S.E. Gitelman, and R. Derynck. 1995. Toward a molecular understanding of skeletal development. Cell 80: 371-378.

Erlebacher, A., E.H. Filvaroff, J.Q. Ye, and R. Derynck. 1998. Osteoblastic responses to TGF-beta during bone remodeling. Mol. Biol. Cell 9: 1903-1918.

Franzoso, G., L. Carlson, L. Xing, L. Poljak, E.W. Shores, K.D. Brown, A. Leonardi, T. Tran, B.F. Boyce, and U. Siebenlist. 1997. Requirement for NF-кB in osteoclast and B-cell development. Genes \& Dev. 11: 3482-3496.

Frost, H.M. 1969. Tetracycline-based histological analysis of bone remodeling. Calcif. Tissue Res. 3: 211-237.

Gelb, B.D., G.P. Shi, H.A. Chapman, and R.J. Desnick. 1996. Pycnodysostosis, a lysosomal disease caused by cathepsin $\mathrm{K}$ deficiency. Science 273: 1236-1238.

Gerber, H.P., T.H. Vu, T.H. Ryan, A.M. Kowalski, Z. Werb, and N. Ferrara. 1999. VEGF couples hypertrophic cartilage remodeling, ossification and angiogenesis during endochondral bone formation.Nat. Med.5: 623-629.

Gergen, J.P. and E. Wieschaus. 1986. Dosage requirements for runt in the segmentation of Drosophila embryos. Cell 45: $289-299$.

Gerondakis, S., R. Grumont, I. Rourke, and M. Grossmann. 1998. The regulation and roles of Rel/NF-кB transcription factors during lymphocyte activation. Curr. Opin. Immunol. 10: $353-359$.

Glimcher, M.J. 1989. Mechanism of clacification: Role of collagen ribrils and collagen-phosphoprotein complexes in vitro and in vivo. Anatomical Rec. 224: 139-153.

Glimcher, M.J., A.J. Hodge, and F.O. Schmitt. 1957. Macromolecular aggregation states in relatin to mineralization: the collagen-hydroxyapatite system as studied in vitro. Proc. Natl. Acad. Sci. 43: 860-866.

Golden, A., S.P. Nemeth, and J.S. Brugge. 1986. Blood platelets express high levels of the pp60c-src-specific tyrosine kinase activity. Proc. Natl. Acad. Sci. 83: 852-856.

Goodman, W.G., J.A. Ramirez, T.R. Belin, Y. Chon, B. Gales, G.V. Segre, and I.B. Salusky. 1994. Development of a dynamic bone in patients with secondary hyperparathyroidism after intermittent calcitriol therapy. Kidney Intl. 46: 11601166.

Grigoriadis, A.E., K. Schellander, Z.Q. Wang, and E.F. Wagner. 1993. Osteoblasts are target cells for transformation in c-fos transgenic mice. J. Cell. Biol. 122: 685-701.

Grigoriadis, A.E., Z.Q. Wang, M.G. Cecchini, W. Hofstetter, R. Felix, H.A. Fleisch, and E.F. Wagner. 1994. c-Fos: a key regulator of osteoclast-macrophage lineage determination and bone remodeling. Science 266: 443-448.

Grigoriadis, A.E., Z.Q. Wang, and E.F. Wagner. 1995. Fos and bone cell development: lessons from a nuclear oncogene. Trends Genet. 11: 436-441.

Hall, B.K. and T. Miyake. 1992. The membranous skeleton: the role of cell condensations in vertebrate skeletogenesis. Anat. Embryol. 186: 107-124.

Hauschka, P.V., J.B. Lian, D.E.C. Cole, and C.M. Gundberg. 1989. Osteocalcin and matrix gla protein: Vitamin K-dependent proteins in bone. In Physiol. Rev. 69: 990-1046.

Hayman, A.R., S.J. Jones, A. Boyde, D. Foster, W.H. Colledge, M.B. Carlton, M.J. Evans, and T.M. Cox. 1996. Mice lacking tartrate-resistant acid phosphatase (Acp 5) have disrupted endochondral ossification and mild osteopetrosis. Development 122: 3151-3162.

Hertwig, P. 1942. Neue mutationen und kopplungsgruppen bei der hausmaus. Z. Indukt. Abstammungs-Vererbungsl. 80: 220-246.

Hodgkinson, C.A., K.J. Moore, A. Nakayama, E. Steingrímsson, N.G. Copeland, N.A. Jenkins, and H. Arnheiter. 1993. Mutations at the mouse microphthalmia locus are associated with defects in a gene encoding a novel basic-helix-loophelix-zipper protein. Cell 74: 395-404.

Hofstetter, W., A. Wetterwald, M.G. Cecchini, C. Mueller, and R. Felix. 1995. Detection of transcripts and binding sites for colony-stimulating factor- 1 during bone development. Bone 17: $145-151$.

Hogan, B.L.M. 1996. Bone morphogenetic proteins: Multifunctional regulators of vertebrate development. Genes \& Dev. 10: $1580-1594$.

Horton, W.A. 1993. Morphology of connective tissue: Cartilage. In Connective tissue and its heritable disorders, pp. 73-84. Wiley-Liss, New York, NY.

Horwood, N.J., V. Kartsogiannis, M.H.X. Lam, E. Romas, J.M.W. Quinn, T.J. Martin, and M.T. Gillespie. 1998. Activated T cells are capable of inducing osteoclast formation: A mechanism for rheumatoid arthritis. In Second Joint Meting of The American Society for Bone and Mineral Research and The International Bone and Mineral Society (ed. M.C. Drezner), pp. S214. Elsevier Science, Inc., San Francisco, CA.

Hou, W.S., D. Bromme, Y. Zhao, E. Mehler, C. Dushey, H. Weinstein, C.S. Miranda, C. Fraga, F. Greig, J. Carey, D.L. Rimoin, R.J. Desnick, and B.D. Gelb. 1999. Characterization of novel cathepsin $\mathrm{K}$ mutations in the pro and mature polypeptide regions causing pycnodysostosis. I. Clin. Invest. 103: 731-738.

Hsu, H., D.L. Lacey, C.R. Dunstan, I. Solovyev, A. Colombero, 
E. Timms, H.L. Tan, G. Elliott, M.J. Kelley, I. Sarosi, L. Wang, X.Z. Xia, R. Elliott, L. Chiu, T. Black, S. Scully, C. Capparelli, S. Morony, G. Shimamoto, M.B. Bass, and W.J. Boyle. 1999. Tumor necrosis factor receptor family member RANK mediates osteoclast differentiation and activation induced by osteoprotegerin ligand. Proc. Natl. Acad. Sci. 96: $3540-3545$.

Huang, L.F., N. Fukai, P.B. Selby, B.R. Olsen, and S. Mundlos. 1997. Mouse clavicular development: analysis of wild-type and cleidocranial dysplasia mutant mice. Dev. Dyn. 210: 3340.

Hunter, G.K., P.V. Hauschka, A.R. Poole, L.C. Rosenberg, and H.A. Goldberg. 1996. Nucleation and inhibition of hydroxyapatite formation by mineralized tissue proteins. Biochem. J. 317: 59-64.

Hurley, D.L., R.D. Tiegs, H.W. Wahner, and H.D. Heath. 1987. Axial and appendicular bone mineral density in patients with long-term deficiency or excess of calcitonin. New Engl. J. Med. 317: 537-541.

Inada, M., T. Yasui, S. Nomura, S. Miyake, K. Deguchi, M. Himeno, M. Sato, H. Yamagiwa, T. Kimura, N. Yasui et al. 1999. Maturational disturbance of chondrocytes in Cbfa1deficient mice. Dev. Dyn. 214: 279-290.

Iotsova, V., J. Caamaño, J. Loy, Y. Yang, A. Lewin, and R. Bravo. 1997. Osteopetrosis in mice lacking NF-кB1 and NF-кB2. Nat. Med. 3: 1285-1289.

Ji, C., S. Casinghino, D.J. Chang, Y. Chen, A. Javed, Y. Ito, S.W. Hiebert, J.B. Lian, G.S. Stein, T.L. McCrthy, and M. Centrella. 1998. CBFa1 (AML/PEBP2)-related elements in the TGF-beta type I receptor promoter and expression with osteoblast differentiation. J. Cell. Biochem. 69: 353-363.

Jimenez, M.J., M. Balbin, J.M. Lopez, J. Alvarez, T. Komori, and C. Lopez-Otin. 1999. Collagenase 3 is a target of Cbfal, a transcription factor of the runt gene family involved in bone formation. Mol. Cell. Biol. 19: 4431-4442.

Jobert, A.S., P. Zhang, A. Couvineau, J. Bonaventure, J. Roume, M. Le Merrer, and C. Silve. 1998. Absence of functional receptors for parathyroid hormone and parathyroid hormonerelated peptide in Blomstrand chondrodysplasia. J. Clin. Invest. 102: 34-40.

Johnson, R.S., B.M. Spiegelman, and V. Papaioannou. 1992. Pleitropic effects of a null mutation in the c-fos proto-oncogene. Cell 71: 577-586.

Jones, S.M. and A.K. Bhalla. 1993. Osteoporosis in rheumatoid arthritis. Clin. Exp. Rheumatol. 11: 557-562.

Jüppner, H., A.B. Abou-Samra, M. Freeman, X.F. Kong, E. Schipani, J. Richards, L.F.J. Kolakowski, J. Hock, J.T.J. Potts, H.M. Kronenberg et al. 1991. A G protein-linked receptor for parathyroid hormone and parathyroid hormone-related peptide. Science 254: 1024-1026.

Karaplis, A.C., A. Luz, J. Glowacki, R.T. Bronson, V.L. Tybulewicz, H.M. Kronenberg, and R.C. Mulligan. 1994. Lethal skeletal dysplasia from targeted disruption of the parathyroid hormone-related peptide gene. Genes \& Dev. 8: $277-$ 289.

Karsenty, G. 1998. Genetics of skeletogenesis. Dev. Gen. 22: 301-313.

Kawasaki, K., Y.H. Gao, S. Yokose, Y. Kaji, T. Nakamura, T. Suda, K. Yoshida, T. Taga, T. Kishimoto, H. Kataoka, T. Yuasa, H. Norimatsu, and A. Yamaguchi. 1997. Osteoclasts are present in gp130-deficient mice. Endocrinology 138: 4959-4965.

Kessler, E., K. Takahara, L. Biniaminov, M. Brusel, and D.S. Greenspan. 1996. Bone morphogenetic protein-1: The type I procollagen C-proteinase. Science 271: 360-362.

Khillan, J.S., A.S. Olsen, S. Kontusaari, B. Sokolov, and D.J.
Prockop. 1991. Transgenic mice that express a mini-gene version of the human gene for type I procollagen (COL1A1) develop a phenotype resembling a lethal form of osteogenesis imperfecta. J. Biol. Chem. 255: 23373-23379.

Kim, I.S., F. Otto, B. Abel, and S. Munmdlos. 1999. Regulation of chondrocyte differentiation by Cbfa1. Mech. Dev. 80: 159-170.

Klemsz, M.J., S.R. McKercher, A. Celada, C. Van Beveren, and R.A. Maki. 1990. The macrophage and B cell-specific transcription factor PU.1 is related to the ets oncogene. Cell 61: 113-124.

Komori, T., H. Yagi, S. Nomura, A. Yamaguchi, K. Sasaki, K. Deguchi, Y. Shimizu, R.T. Bronson, Y.H. Gao, M. Inada et al. 1997. Targeted disruption of Cbfal results in a complete lack of bone formation owing to maturational arrest of osteoblasts. Cell 89: 755-764.

Kong, Y.Y., H. Yoshida, I. Sarosi, H.L. Tan, E. Timms, C. Capparelli, S. Morony, A.J. Oliveira-dos-Santos, G. Van, A. Itie et al. 1999. OPGL is a key regulator of osteoclastogenesis, lymphocyte development and lymph-node organogenesis. $\mathrm{Na}$ ture 397: 315-323.

Lacey, D.L., E. Timms, H.L. Tan, M.J. Kelley, C.R. Dunstan, T. Burgess, R. Elliott, A. Colombero, G. Elliott, S. Scully et al. 1998. Osteoprotegerin ligand is a cytokine that regulates osteoclast differentiation and activation. Cell 93: 165-176.

Lagasse, E. and I.L. Weissman. 1997. Enforced expression of Bcl-2 in monocytes rescues macrophages and partially reverses osteopetrosis in op/op mice. Cell 89: 1021-1031.

Lanske, B., M. Amling, L.Neff, J. Guiducci, R. Baron, and H.M. Kronenberg. 1999. Ablation of the PTHrP gene or the PTH/ PTHrP receptor gene leads to distinct abnormalities in bone development. J. Clin. Invest. 104: 399-407.

Lee, B., K. Thirunavukkarasu, L. Zhou, L. Pastore, A. Baldini, J. Hecht, V. Geoffroy, P. Ducy and G. Karsenty. 1997a. Missense mutations abolishing DNA binding of the osteoblastspecific transcription factor OSF2/Cbfa1 in cleidocranial dysplasia. Nat. Genet. 16: 307-310.

Lee, S., D.E. Solow-Cordero, E. Kessler, K. Takahara, and D.S. Greenspan. 1997b. Transforming growth factor-beta regulation of bone morphogenetic protein-1/procollagen C-proteinase and related proteins in fibrogenic cells and keratinocytes. J. Biol. Chem. 272: 19056-19066.

Levanon, D., V. Negreanu, Y. Bernstein, I. Bar-Am, L. Avivi, and Y. Groner. 1994. AML1, AML2, and AML3, the human members of the runt domain gene-family: cDNA structure, expression, and chromosomal localization. Genomics 23: 425-432.

Li, Y.C., A.E. Pirro, M. Amling, G. Delling, R. Baron, R. Bronson, and M.B. Demay. 1997. Targeted ablation of the vitamin $\mathrm{D}$ receptor: An animal model of vitamin D-dependent rickets type II with alopecia. Proc. Nat1. Acad. Sci. 94: 98319835.

Li, Y.C., M. Amling, A.E. Pirro, M. Priemel, J. Meuse, R. Baron, G. Delling, and M.B. Demay. 1998. Normalization of mineral ion homeostasis by dietary means prevents hyperparathyroidism, rickets, and osteomalacia, but not alopecia in vitamin D receptor-ablated mice. Endocrinology 139: 43914396.

Liaw, E. Birk, C.B. Ballas, J.S. Whitsitt, J.M. Davidson, and B.L. Hogan. 1998. Altered wound healing in mice lacking a functional osteopontin gene (spp1). J. Clin. Invest. 101: 14681478.

Liu, X., H. Wu, M. Byrne, J. Jeffrey, S. Krane, and R. Jaenisch. 1995. A targeted mutation at the known collagenase cleavage site in mouse type I collagen impairs tissue remodeling. J. Cell. Biol. 130: 227-237. 
Lomaga, M.A., W.C. Yeh, I. Sarosi, G.S. Duncan, C. Furlonger, A. Ho, S. Morony, C. Capparelli, G. Van, S. Kaufman et al. 1999. TRAF6 deficiency results in osteopetrosis and defective interleukin-1, CD40, and LPS signaling. Genes \& Dev. 13: $1015-1024$.

Lowe, C., T. Yoneda, B.F. Boyce, H. Chen, G. Mundy, and P. Soriano. 1993. Osteopetrosis in Src-deficient mice is due to an autonomous defect of osteoclasts. Proc. Natl. Acad. Sci. 15: 4485-4489.

Lowell, C.A. and P. Soriano. 1996. Knockouts of Src-family kinases: Stiff bones, wimpy T cells, and bad memories. Genes \& Dev. 10: $1845-1857$.

Luo, G., P. Ducy, M.D. McKee, G.J. Pinero, E. Loyer, R.R. Behringer, and G. Karsenty. 1997. Spontaneous calcification of arteries and cartilage in mice lacking matrix GLA protein. Nature 386: 78-81.

Manolagas, S.C., R.L. Jilka, T. Bellido, C.A. O'Brien, and A.M. Parfitt. 1996. Interleukin-6-type cytokines and their receptors. In Principles of bone biology (ed. J.P. Bilezikian, L.G. Raisz, G.A. Rodan), pp. 701-713. Academic Press, San Diego, CA.

Marini, J.C., S. Bordenick, G. Heavner, S. Rose, R. Hintz, R. Rosenfeld, and G.P. Chrousos. 1993. The growth hormone and somatomedin axis in short children with osteogenesis imperfecta. J. Clin. Endocrinol. Metab. 76: 251-256.

Marks, S.C.J. and P.W. Lane. 1976. Osteopetrosis, a new recessive skeletal mutation on chromosome 12 of the mouse. $J$. Hered. 67: 11-18.

Marks, S.C.J., M.F. Seifert, and J.L. McGuire. 1984. Congenitally osteopetrotic (op/op) mice are not cured by transplants of spleen or bone marrow cells from normal littermates. Metab. Bone Dis. Relat. Res. 5: 183-186.

McKercher, S.R., B.E. Torbett, K.L. Anderson, G.W. Henkel, D.J. Vestal, H. Baribault, M. Klemsz, A.J. Feeney, G.E. Wu, C.J. Paige, and R.A. Maki. 1996. Targeted disruption of the PU.1 gene results in multiple hematopoietic abnormalities. EMBO J. 15: 5647-5658.

Mizuno, A., N. Amizuka, K. Irie, A. Murakami, N. Fujise, T. Kanno, Y. Sato, N. Nakagawa, H. Yasuda, S. Mochizuki et al. 1998. Severe osteoporosis in mice lacking osteoclastogenesis inhibitory factor/osteoprotegerin. Biochem. Biophys. Res. Comm. 247: 610-615.

Mundlos, S., F. Otto, C. Mundlos, J.B. Mulliken, A.S. Aylsworth, S. Albright, D. Lindhout, W.G. Cole, W. Henn, J.H. Knoll et al. 1997. Mutations involving the transcription factor CBFA1 cause cleidocranial dysplasia. Cell 89: 773-779.

Mundy, G.R., B.F. Boyce, T. Yoneda, L.F. Bonewald, and G.D. Roodman. 1996. Cytokines and bone remodeling (ed. R. Marcus, D. Feldman, J. Kelsey). pp. Academic Press, San Diego, CA.

Narisawa, S., N. Fröhlander, and J.L. Millán. 1997. Inactivation of two mouse alkaline phosphatase genes and establishment of a model of infantile hypophosphatasia. Dev. Dyn. 208: 432-446.

Ogawa, E., M. Maruyama, H. Kagoshima, M. Inuzuka, J. Lu, M. Satake, K. Shigesada, and Y. Ito. 1993. PEBP2/PEA2 represents a family of transcription factors homologous to the products of the Drosophila runt gene and the human AML1 gene. Proc. Natl. Acad. Sci. 90: 6859-6863.

Oldberg, A., A. Franzén, and D. Heinegård. 1986. Cloning and sequence analysis of rat bone sialoprotein (osteopontin) cDNA reveals an Arg-Gly-Asp cell-binding sequence. Proc. Nat1. Acad. Sci. 83: 8819-8823.

Oreffo, R.O., V. Kusec, A.S. Virdi, A.M. Flanagan, M. Grano, A. Zambonin-Zallone, and J.T. Triffitt. 1999. Expression of estrogen receptor-alpha in cells of the osteoclastic lineage. His- tochem. Cell. Biol. 111: 125-133.

Otto, F., A.P. Thornell, T. Crompton, A. Denzel, K.C. Gilmour, I.R. Rosewell, G.W. Stamp, R.S. Beddington, S. Mundlos, B.R. Olsen, P.B. Selby, and M.J. Owen. 1997. Cbfa1, a candidate gene for cleidocranial dysplasia syndrome, is essential for osteoblast differentiation and bone development. Cell 89: 765-771.

Oursler, M.J., P. Osdoby, J. Pyfferoen, B.L. Riggs, and T.C. Spelsberg. 1991. Avian osteoclasts as estrogen target cells. Proc. Natl. Acad. Sci. 88: 6613-6617.

Owens, J.M., K. Matsuo, G.C. Nicholson, E.F. Wagner, and T.J. Chambers. 1999. Fra-1 potentiates osteoclastic differentiation in osteoclast-macrophage precursor cell lines. J. Cell. Physiol. 179: 170-178.

Pacifici, R. 1998. Cytokines, estrogen, and postmenopausal osteoporosis-the second decade. Endocrinology 139: 26592661.

Piepkorn, B., P. Kann, T. Forst, J. Andreas, A. Pfützner, and J. Beyer. 1997. Bone mineral density and bone metabolism in diabetes mellitus. Hormone Metab. Res. 29: 584-591.

Porte, D., J. Tuckermann, M. Becker, B. Baumann, S. Teurich, T. Higgins, M.J. Owen, M. Schorpp-Kistner, and P. Angel. 1999. Both AP-1 and Cbfal-like factors are required for the induction of interstitial collagenase by parathyroid hormone. Oncogene 18: 667-678.

Prockop, D.J., H. Kuivaniemi, and G. Tromp. 1994. Molecular basis of osteogenesis imperfecta and related disorders of bone. Clin. Plastic Surg. 21: 407-413.

Rifas, L., L.S. Holliday, S.L. Gluck, and L.V. Aviolo. 1998. Activated T cells induce osteoclastogenesis. In Second Meeting of the The American Society for Bone and Mineral Research and The International Bone and Mineral Society (ed. M.C. Drezner), pp. S195. Elsevier Science, Inc., San Francisco, CA.

Rittling, S.R., H.N. Matsumoto, M.D. McKee, A. Nanci, X.R. An, K.E. Novick, A.J. Kowalski, M. Noda, and D.T. Denhardt. 1998. Mice lacking osteopontin show normal development and bone structure but display altered osteoclast formation in vitro. J. Bone Min. Res. 13: 1101-1111.

Rodan, G., L.G. Raisz, and J.P. Bilezikian. 1996. Pathophysiology of osteoporosis. In Principles of bone biology (ed. J.P. Bilezikian, L.G. Raisz, G. Rodan), pp. 979-990. Academic Press, San Diego, CA.

Rossert, J., H. Eberspaecher and B. De Crombrugghe. 1996. Separate cis-acting DNA elements of the mouse pro-alpha1 (i) collagen promoter direct expression of reporter genes to different type I collagen-producing cells in transgenic mice. $J$. Cell. Biol. 129: 1421-1432.

Saftig, P., E. Hunziker, O. Wehmeyer, S. Jones, A. Boyde, W. Rommerskirch, J.D. Moritz, P. Schu, and K. von Figura. 1998. Impaired osteoclastic bone resorption leads to osteopetrosis in cathepsin-K-deficient mice. Proc. Natl. Acad. Sci. 95: 13453-13458.

Schinke, T. and G. Karsenty. 1999. Characterization of Osf1, an osteoblast-specific transcription factor binding to a critical cis-acting element in the mouse osteocalcin promoter. $J$. Biol. Chem. 274: 30182-30189.

Schwartzberg, P.L., L. Zing, O. Hoffman, C.A. Lowell, L. Garrett, B.F. Boyce, and H.D. Varmus. 1997. Rescue of osteoclast function by transgenic expression of kinase-deficient Src in $\mathrm{src}^{-/-}$mutant mice. Genes \& Dev. 11: 2835-2844.

Scott, E.W., M.C. Simon, J. Anastasi, and H. Singh. 1994. Requirement of transcription factor PU.1 in the development of multiple hematopoietic lineages. Science 265: 1573-1577.

Seligman, M., R.F. Eilberg, and L. Fishman. 1975. Mineralization of elastin extracted from human aortic tissues. Calcif. Tissue Res. 17: 229-234. 
Sherr, C.J., C.W. Rettenmier, R. Sacca, M.F. Roussel, A.T. Look, and E.R. Stanley. 1985. The c-fms proto-oncogene product is related to the receptor for the mononuclear phagocyte growth factor, CSF-1. Cell 41: 665-676.

Shimell, M.J., E.L. Ferguson, S.R. Childs, and M.B. O'Connor. 1991. The Drosophila dorsal-ventral patterning gene tolloid is related to human bone morphogenetic protein 1. Cell 67: 469-481.

Sillence, D.O., H.E. Ritchie, and P.B. Selby. 1987. Animal model: Skeletal anomalies in mice with cleidocranial dysplasia. Am. J. Med. Genet. 27: 75-85.

Simonet, W.S., D.L. Lacey, C.R. Dunstan, M. Kelley, M.S Chang, R. Lüthy, H.Q. Nguyen, S. Wooden, L. Bennett, T. Boone et al. 1997. Osteoprotegerin: A novel secreted protein involved in the regulation of bone density. Cell 89: 309-319.

Slatopolsky, E. and J.A. Delmez. 1998. Renal Osteodystrophy. In Metabolic bone disease and clinically related disorders (ed. L.F. Aviolo and S.M. Krane), pp. 443-463. Academic Press, San Diego, CA.

Soriano, P., C. Montgomery, R. Geske, and A. Bradley. 1991. Targeted disruption of the c-src proto-oncogene leads to osteopetrosis in mice. Cell 64: 693-702.

Speck, N.A. and T. Stacy. 1995. A new transcription factor family associated with human leukemias. CRC Crit. Rev. Eukaryot. Gene Expression 5: 337-364.

St-Jacques, B., M. Hammerschmidt, and A.P. McMahon. 1999. Indian hedgehog signaling regulates proliferation and differentiation of chondrocytes and is essential for bone formation. Genes \& Dev. 13: 2072-2086.

Suda, T., N. Udagawa, and N. Takahashi. 1996. Cells of bone: osteoclast generation. In Principles of bone biology (ed. J.P. Bilezikian, L.G. Raisz, G.A. Rodan), pp. 87-102. Academic Press, San Diego, CA.

Suzuki, N., P.A. Labosky, Y. Furuta, L. Hargett, R. Dunn, A.B. Fogo, K. Takaharar, D.M. Peters, D.S. Greenspan, and B.L. Hogan. 1996. Failure of ventral body wall closure in mouse embryos lacking a procollagen C-proteinase encoded by Bmp1, a mammalian gene related to Drosophila tolloid. Development 122: 3587-3595.

Tanaka, S., M. Amling, L. Neff, A. Peyman, E. Uhlmann, J.B. Levy, and R. Baron. 1996. c-Cbl is downstream of c-Src in a signalling pathway necessary for bone resorption. Nature 383: $528-531$.

Teitelbaum, S.L., M.M. Tondravi, and F.P. Ross. 1996. Osteoclast biology. In Osteoporosis (ed. R. Marcus, D. Feldman, J. Kelsey), pp. 61-94. Academic Press, San Diego, CA.

Tondravi, M.M., S.R. McKercher, K. Anderson, J.M. Erdmann, M. Quiroz, R. Maki, and S.L. Teitelbaum. 1997. Osteopetrosis in mice lacking haematopoietic transcription factor PU.1. Nature 386: 81-84.

Verma, I.M., J.K. Stevenson, E.M. Schwarz, D. Van Antwerp, and S. Miyamoto. 1995. Rel/NF-кB/ІкB family: Intimate tales of association and dissociation. Genes \& Dev. 9: 2723 2735.

Vortkamp, A., K. Lee, B. Lanske, G.V. Segre, H.M. Kronenberg, and C.J. Tabin. 1996. Regulation of rate of cartilage differentiation by Indian hedgehog and PTH-related protein. Science 273: 613-622.

Vu, T.H., J.M. Shipley, G. Bergers, J.E. Berger, J.A. Helms, D. Hanahan, S.D. Shapiro, R.M. Senior, and Z. Werb. 1998. MMP-9/gelatinase B is a key regulator of growth plate angiogenesis and apoptosis of hypertrophic chondrocytes. Cell 93: 411-422.

Wang, Z.Q., C. Ovitt, A.E. Grigoriadis, U. Möhle-Steinlein, U. Rüther, and E.F. Wagner. 1992. Bone and haematopoietic defects in mice lacking c-fos. Nature 360: 741-745.
Ward, J.M. and D.M. Young. 1976. Histogenesis and morphology of periosteal sarcomas induced by FBJ virus in NIH Swiss mice. Cancer Res. 36: 3985-3992.

Warshawsky, H. 1982. Embryology and development of the skeletal system. In The Musculoskeletal System: Embryology, biochemistry and physiology, pp. 33-56. Churchill Livingston Press, New York, NY.

Waymire, K.G., J.D. Mahuren, J.M. Jaje, T.R. Guilarte, S.P. Coburn, and G.R. MacGregor. 1995. Mice lacking tissue nonspecific alkaline phosphatase die from seizures due to defective metabolism of vitamin B-6. Nat. Genet. 11: 45-51.

Whyte, M.P. 1994. Hypophosphatasia and the role of alkaline phosphatase in skeletal mineralization. Endocrin. Rev. 15: 439-461.

Wimalawansa, S.J. 1997. Amylin, calcitonin gene-related peptide, calcitonin, and adrenomedullin: A peptide superfamily. CRC Crit. Rev. Neurobiol.11: 167-239.

Wong, B.R., R. Josien, S.Y. Lee, M. Vologodskaia, R.M. Steinman, and Y. Choi. 1998. The TRAF family of signal transducers mediates NF- $\mathrm{B}$ activation by the TRANCE receptor. J. Biol. Chem. 273: 28355-28359.

$\mathrm{Xu}, \mathrm{T} ., \mathrm{P}$. Bianco, L.W. Fisher, G. Longenecker, E. Smith, S. Goldstein, J. Bonadio, A. Boskey, A.M. Heegaard, B. Sommer et al. 1998. Targeted disruption of the biglycan gene leads to an osteoporosis-like phenotype in mice. Nat. Genet. 20: 7882.

Yasuda, H., N. Shima, N. Nakagawa, S.I. Mochizuki, K. Yano, N. Fujise, Y. Sato, M. Goto, K. Yamaguchi, M. Kuriyama et al. 1998. Identity of osteoclastogenesis inhibitory factor (OCIF) and osteoprotegerin (OPG): A mechanism by which OPG/OCIF inhibits osteoclastogenesis in vitro. Endocrinol ogy 139: 1329-1337.

Yoshida, H., S. Hayashi, T. Kunisada, M. Ogawa, S. Nishikawa, H. Okamura, T. Sudo, L.D. Schulz, and S. Nishikawa. 1990. The murine mutation osteopetrosis is in the coding region of the macrophage colony stimulating factor gene. Nature 345: 442-444.

Yoshizawa, T., Y. Handa, Y. Uematsu, S. Takeda, K. Sekine, Y. Yoshihara, T. Kawakami, K. Arioka, H. Sato, Y. Uchiyama et al. 1997. Mice lacking the vitamin D receptor exhibit impaired bone formation, uterine hypoplasia and growth retardation after weaning. Nat. Genet. 16: 391-396.

Zhao, W., M.H. Byrne, B.F. Boyce, and S.M. Krane. 1999. Bone resorption induced by parathyroid hormone is strikingly diminished in collagenase-resistant mutant mice. J. Clin. Invest. 103: 517-524. 


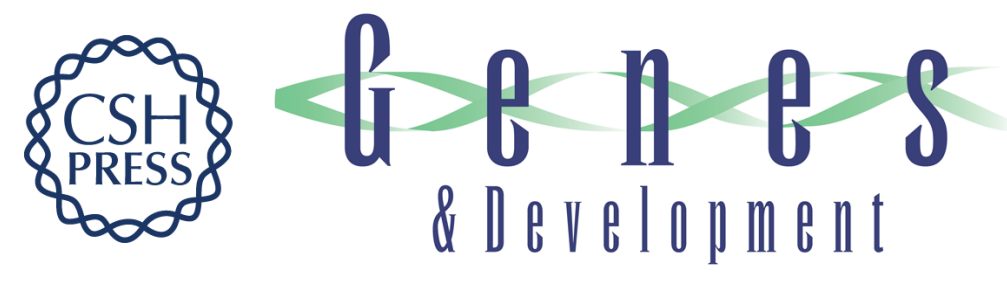

\section{The genetic transformation of bone biology}

Gerard Karsenty

Genes Dev. 1999, 13:

References This article cites 133 articles, 43 of which can be accessed free at: http://genesdev.cshlp.org/content/13/23/3037.full.html\#ref-list-1

License

Email Alerting Receive free email alerts when new articles cite this article - sign up in the box at the top Service right corner of the article or click here.

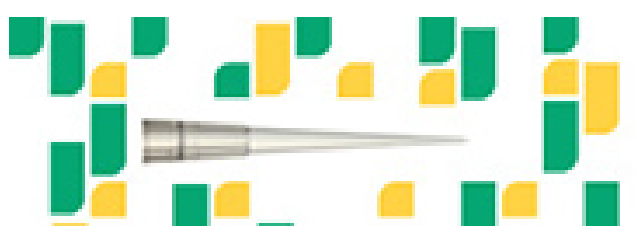

Focused on your science. 